
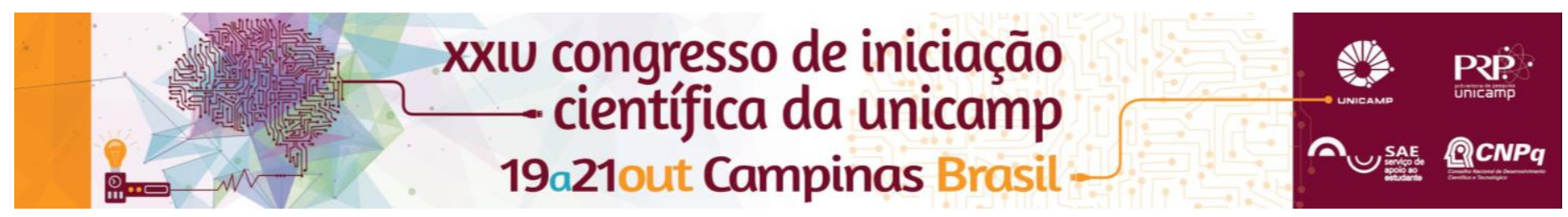

\title{
Sistemas Dinâmicos Lineares por Partes: Teoria Local e Global.
}

\section{Ricardo M. Martins (PQ), Matheus M. de Castro (IC).}

\section{Resumo}

Neste trabalho foi feita uma introdução ao estudo da teoria de sistemas dinâmicos, se focando-se em campos definidos na esfera e no toro. Os resultados principais são teoremas envolvendo a dinâmica de campos constantes definidos por partes na esfera, e resultados da dinâmica de campos polinomiais divergentes e Hamiltonianos definidos no toro.

\section{Palavras-chave:}

Sistemas Dinâmicos, Campos Polinomiais, Retrato de Fase.

\section{Introdução}

Pode-se facilmente definir Sistemas Dinâmicos por meio de Equações Diferenciais. Quando se trata de defini-las na Esfera ou no Toro, isso torna-se complicado por meio de suas parametrizações. Pode-se contornar esse problema fazendo uso de uma relação de equivalência adequada que relaciona os pontos, respectivamente, da Esfera e do Toro, com pontos de um triângulo e de um quadrado no plano real.

Após essa correspondência feita a pergunta natural é quais propriedades pode-se tirar de campos definidos nesses espaços. Sendo esta a questão que o projeto pretende responder.

\section{Resultados e Discussão}

Dentro do âmbito dos sistemas dinâmicos foram estudados tópicos como: pontos de singularidade, fluxo de um sistema de equações diferenciais, retratos de fase, ideias básicas da teoria qualitativa, análise de órbitas e caracterização de ciclos limites.

Além disso dois teoremas importantes de sistemas dinâmicos foram debatidos: os teoremas de Poincaré-Bendixson e de Poincaré-Hopf.

Teorema (Poincaré-Bendixson) Dado um sistema dinâmico definido em um subespaço aberto do plano, todo conjunto $\omega$-limite compacto e não vazio que contém apenas um número finito de singularidades é uma singularidade, uma órbita periódica ou um conjunto conexo composto de um número finito de singularidades com órbitas homoclínicas e heteroclínicas se conectando a elas.

Utilizando esses conhecimentos e esse teorema foi possível provar os teoremas:

Teorema Seja $F: \mathbb{R}^{2} \rightarrow \mathbb{T}^{2}$ um campo polinomial de primeira ordem e considere o sistema $y^{\prime}=F(y)$. Então temos que:

- Se $F$ é um campo divergente, então o retrato de fase do sistema possui, genericamente, duas selas e dois nós (um estável e um instável).
- Se $F$ for hamiltoniano, o retrato de fase do sistema possui sempre possui duas selas e dois centros. Além disso, se a razão entre os termos independentes de $F$ pertencer aos racionais, então as órbitas que não são homoclínicas ou singularidades são periódicas; caso contrário tais órbitas tem as homoclínicas como $\alpha$ - ou $\omega$-limite.

Teorema Considere a esfera obtida a partir de um tetraedro e seja $F: \mathbb{R}^{2} \rightarrow \mathbb{S}^{2}$ um campo vetorial definido por partes na esfera, com $\mathrm{F}$ constante em cada lado do tetraedro. Então, genericamente: a) todas as configurações possíveis de regiões de costura e deslizantes são realizáveis e b) $F$ não pode ter todas as trajetórias periódicas.

\section{Conclusão}

Os Teoremas de Poincaré-Bendixson e Poincaré-Hopf são ferramentas muito poderosas no estudo dos Sistemas Dinâmicos, possibilitando demonstrar resultados essenciais dessa área.

\section{Agradecimentos}

Gostaria de agradecer ao PIBIC / CNPq / UNICAMP pela oportunidade, e ao meu Orientador pelo suporte e atenção.

[1] J. Llibre, A. E. Teruel, Introduction to the Qualitavie Theory of Differencial Systems: Planar, Symmetric and Continuous Prieciewise Linear Systems, Birkhauser, 2014. $289 \mathrm{p}$.

[2] Otávio Marçal Leandro Gomide, Ciclos Limites em Sistemas Dinâmicos Suaves e Nâo-Suaves, Universidade Estadual de Campinas, UNICAMP, 2015.

[3] O. Makarenkov, J. S. W. Lamb, Dynamics and bifurcations of non smooth systems: A survey, Physica D: Nonlinear Phenomena, vol. 241, 1826-1844, 2012.

[4] M. P. do Carmo, Geometria Diferencial de Curvas e Superficies, Textos Universitários, SBM, 2011. 